\title{
ASSOCIATION OF STEROID RECEPTOR EXPRESSION WITH THE CLINICAL AND HISTOLOGICAL FINDINGS IN PATIENTS WITH ENDOMETRIAL CANCER
}

\author{
Aisha Shahid, Ghulam Haider, Paras Memon, Shumyla Beg, Mehwish Shahzadi*, Kiran Abbas \\ Jinnah Postgraduate Medical Center, Karachi Pakistan, *Aga Khan University, Karachi Pakistan
}

\section{ABSTRACT}

\begin{abstract}
Objective: To determine the association of estrogen and progesterone receptor expression with the clinical and histological findings of endometrial cancer.

Study Design: Prospective observational study.

Place and Duration of Study: Jinnah Postgraduate Medical Centre, Karachi between Sep 2017 to Oct 2019.

Methodology: A total of 130 patients were diagnosed with endometrial carcinoma. Data from patient files were collected regarding tumour histology, grade, stage, tumour receptor expression, and the clinical characteristics: parity, menopausal status. The receptor expression profile was documented for each patient. Data were analyzed using SPSS version 25 . The association between ER/PR expression categories and clinical/histological features were explored using the chi-square test.

Results: The estrogen and progesterone receptor expressions were significantly associated with low-grade (Grade I and II) tumours and with Stage I and Stage II endometrial carcinoma with $p<0.001$. About 34 (34.7\%) cases of endometrioid histology were negative for both estrogen and progesterone receptors. The ER and PR negativity was strongly associated with Grade III endometrial cancer $(p=0.003)$. The majority of the stage IV cancers were negative for both the ER and PR receptors with a $p<0.001$.

Conclusion: Estrogen and progesterone positivity was associated with endometrioid adenocarcinoma, well-differentiated, and less advanced stage of endometrial cancer at the time of diagnosis.
\end{abstract}

Keywords: Endometrial carcinoma, Endometrioid cancer, Estrogen, ER expression, Progesterone, PR expression.

How to Cite This Article: Shahid A, Haider G, Memon P, Beg S, Shahzadi M, Abbas K. Association of Steroid Receptor Expression with The Clinical and Histological Findings in Patients with Endometrial Cancer. Pak Armed Forces Med J 2021; 71(5): 1875-1879. _ doi: https://doi.org/10.51253/pafmj.v71i5.5802

This is an Open Access article distributed under the terms of the Creative Commons Attribution License (https://creativecommons.org/licenses/by-nc/4.0/), which permits unrestricted use, distribution, and reproduction in any medium provided the original work is properly cited.

\section{INTRODUCTION}

Endometrial cancer is a tumour arising in the inner lining of the uterus. More than $90 \%$ of uterine cancers occur in the endometrium. It is the sixth most frequent malignancy worldwide, preceded by cancers such as that of the breast, colon, rectum, and lung ${ }^{1}$. In developed countries, like the United States, it is a leading cause of death. A much lower incidence is found in developing countries in Asia, Africa, and South America $^{2}$. In the United States, an estimated 61,880 women were diagnosed with endometrial cancer this year.

The frequency of cases of endometrial carcinoma among women is on the rise due to increasing obesity, which is a well-known modifiable risk factor for this cancer. Certain other factors are known to increase the risk of developing endometrial carcinoma including, anovulation, early menarche, late menopause, diabetes mellitus, unopposed estrogen, hormonal replacement therapy, lack of physical exercise, and heavy smoking?

The most common manifestation of the cancer is postmenopausal vaginal bleeding. Endometrial cancer

Correspondence: Dr Aisha Shahid, Department of Oncology, Jinnah Postgraduate Medical Center, Karachi Pakistan

Received: 06 Dec 2020; revision received: 21 Jun 2021; accepted: 02 Jul 2021 is rare in patients younger than 35 years of age 4 . The majority of patients with endometrial carcinoma are in their fifth or sixth decade at the time of the diagnosis. The mean age of endometrial carcinoma is about 60 years.

There are two main types of endometrial cancer. One of these types is estrogen-dependent, which occurs in younger women. Endometrioid histological subtypes constitute the majority of these tumours. These cancers are often low-grade and associated with a favourable prognosis while the other group consists of more aggressive variants of this disease (serous and clear cell type) with a worse prognosis 5 . The former develops under the influence of endometrial hyperplasia while the latter is associated with endometrial atrophy.

Women with existing breast cancer are more at risk of developing concomitant endometrial cancer. Reproductive and hormonal disturbances such as postmenopausal estrogen levels or BMI are strongly associated with breast and endometrial cancers and weakly with ovarian cancers. This may explain the co-existence of these cancers. Due to diversity in histopathological features of endometrial carcinoma, the clinical course and outcome may greatly vary accordingly ${ }^{6}$. 
A cancer is called estrogen-receptor-positive (or $\mathrm{ER}+$ ) if it has receptors for estrogen. This suggests that the cancer cells, like normal breast cells, may receive signals from estrogen that could promote their growth. The cancer is progesterone-receptor-positive (PR+) if it has progesterone receptors. Both estrogen and progesterone hormone receptors have significant positive associations with prognosis, clinical outcome, and survival rates7,8. In the present study, the association of ER and PR positivity of endometrial cancer with the clinical and histological characteristics have been explored.

\section{METHODOLOGY}

This was a prospective, observational study conducted at the Oncology Ward, Jinnah Postgraduate Medical Center, the largest public sector tertiary care hospital in Karachi, Sindh, from Sep 2017 to Oct 2019. Ethical approval from the Institutional Review Board (\#F2-81-IRB/2017-GENL/161/JPMC) was taken from JPMC Research Department. A non-randomized consecutive sampling technique was employed to recruit participants into the study.

Inclusion Criteria: The study included clinically diagnosed endometrial cancer cases with estrogen and progesterone receptor status.

Exclusion Criteria: All the patients with incomplete receptor expression profile, clinical or histological data were excluded from the study. Patients with undiagnosed or suspicious lesions were also not included in the study.

The incidence of endometrial carcinoma was reported to be $2 \%$ in recent study by Abid et al, which was kept as the reference for calculating the sample size for the study 9 . By keeping the confidence level of $95 \%$, a margin of error as 2.41 , and a population of 100,000 , a sample size of 130 was obtained. All surgical specimens were immunohistochemically analyzed to determine the estrogen and progesterone receptors status. Age, ethnicity, any known comorbidity, reproductive history, histology, grade, stage, and ER/PR status of the cancer was recorded. All data was recorded in a predefined proforma.

The data was analyzed using the SPSS-25. The chi-square test was performed to observe statistical significance among variables. The hormone receptor status was categorized into 2 main groups i.e., ER positive PR positive and ER negative PR negative. The $p$ value of $\leq 0.05$ was considered as significant. Data was presented as graphs and in tabular form.

\section{RESULTS}

A total of 130 women were diagnosed with endometrial carcinoma during the study period. The mean age of patients was $53.07 \pm 11.04$ years. The majority of them were Urdu speaking with a frequency of 70

Table-I: Demographic and clinical profile of study participants $(n=130)$.

\begin{tabular}{|c|c|}
\hline Characteristics & $\mathrm{n}(\%)$ \\
\hline Age in years $($ Mean \pm SD) & $53.07 \pm 11.04$ \\
\hline \multicolumn{2}{|l|}{ Ethnicity } \\
\hline Urdu Speaking & $70(53.8 \%)$ \\
\hline Punjabi & $28(21.5 \%)$ \\
\hline Sindhi & $14(10.8 \%)$ \\
\hline Pushtoon & $10(7.7 \%)$ \\
\hline Other & $8(6.2 \%)$ \\
\hline \multicolumn{2}{|l|}{ Menopausal Status } \\
\hline Premenopausal & $26(20 \%)$ \\
\hline Postmenopausal & $104(80 \%)$ \\
\hline \multicolumn{2}{|l|}{ Parity } \\
\hline Nulliparous & $16(12.3 \%)$ \\
\hline 1 child only & $38(29.2 \%)$ \\
\hline 2-3 children only & $36(27.7 \%)$ \\
\hline 4 or more children & $40(30.8 \%)$ \\
\hline \multicolumn{2}{|l|}{ Comorbidity } \\
\hline Hypertension (HTN) & $28(21.5 \%)$ \\
\hline Diabetes Mellitus (DM) & $8(6.2 \%)$ \\
\hline Concomitant HTN \& DM & $18(13.8 \%)$ \\
\hline No Known Comorbidity (NKCM) & $76(58.5 \%)$ \\
\hline \multicolumn{2}{|l|}{ Family History of Cancer } \\
\hline Positive & $45(34.6 \%)$ \\
\hline Negative & $85(65.4 \%)$ \\
\hline \multicolumn{2}{|c|}{ Histological Variant of Endometrial Cancer } \\
\hline Endometrioid adenocarcinoma & $98(75.4 \%)$ \\
\hline Serous & $14(10.8 \%)$ \\
\hline Clear cell & $8(6.2 \%)$ \\
\hline Other & $10(7.7 \%)$ \\
\hline \multicolumn{2}{|l|}{ Stage of Endometrial Cancer } \\
\hline Stage I & $30(23.1 \%)$ \\
\hline Stage II & $18(13.8 \%)$ \\
\hline Stage III & $28(21.5 \%)$ \\
\hline Stage IV & $54(41.5 \%)$ \\
\hline \multicolumn{2}{|l|}{ Grade of Cancer } \\
\hline Grade I or Well-differentiated & $24(18.5 \%)$ \\
\hline Grade II or Moderately differentiated & $56(43.1 \%)$ \\
\hline Grade III or Poorly differentiated & $50(38.5 \%)$ \\
\hline \multicolumn{2}{|l|}{ Hormonal Receptor Status } \\
\hline ER positive, PR positive & $66(50.8 \%)$ \\
\hline ER negative, PR negative & $54(41.5 \%)$ \\
\hline Only ER positive & $6(4.6 \%)$ \\
\hline Only PR negative & $4(3.1 \%)$ \\
\hline
\end{tabular}

(53.8\%), followed by Punjabi, 28 (21.5\%) other ethnicities. Twenty-six (20\%) women were premenopausal at the time of diagnosis while, the majority of them i.e., $104(80 \%)$ of the patients were postmenopausal (TableI). 
Hypertension was reported to be the most frequently presented comorbidity with a frequency of status were not statistically associated with ER and PR expression in the present study (Table-II \& III).

\begin{tabular}{|c|c|c|c|c|c|c|c|}
\hline \multicolumn{8}{|c|}{ ER \& PR Positive } \\
\hline Parameters & Yes & No & $p$-value & Parameters & Yes & No & $p$-value \\
\hline \multicolumn{4}{|c|}{ Histological Variant } & \multicolumn{4}{|c|}{ Histological Variant } \\
\hline Endometrioid & $60(61.22 \%)$ & $38(38.78 \%)$ & \multirow{3}{*}{$<0.001$} & Endometrioid & $34(34.7 \%)$ & $64(65.3 \%)$ & \multirow{3}{*}{0.005} \\
\hline Serous & - & $14(100 \%)$ & & Serous & $10(71.4 \%)$ & $4(28.6 \%)$ & \\
\hline Clear cell & - & $8(100 \%)$ & & Clear cell & $6(75 \%)$ & $2(25 \%)$ & \\
\hline \multicolumn{4}{|l|}{ Parity } & \multicolumn{4}{|l|}{ Parity } \\
\hline Nulliparous & $8(50 \%)$ & $8(50 \%)$ & \multirow{2}{*}{0.947} & Nulliparous & $6(37.5 \%)$ & $10(62.5 \%)$ & \multirow{2}{*}{0.726} \\
\hline Parous & $58(50.88 \%)$ & $56(49.12 \%)$ & & Parous & $48(42.1 \%)$ & $66(57.9 \%)$ & \\
\hline \multicolumn{4}{|l|}{ Menopausal Status } & \multicolumn{4}{|l|}{ Menopausal Status } \\
\hline Premenopausal & $14(53.85 \%)$ & $12(46.15 \%)$ & \multirow{2}{*}{0.725} & Premenopausal & $14(53.8 \%)$ & $12(46.2 \%)$ & \multirow{2}{*}{0.215} \\
\hline Postmenopausal & $52(50 \%)$ & $52(50 \%)$ & & Postmenopausal & $42(40.4 \%)$ & $62(59.6 \%)$ & \\
\hline \multicolumn{4}{|l|}{ Grade } & \multicolumn{4}{|l|}{ Grade } \\
\hline Grade I & $18(75 \%)$ & $6(25 \%)$ & \multirow{3}{*}{$<0.001$} & Grade I & $6(25.0 \%)$ & $18(75 \%)$ & \multirow{3}{*}{0.003} \\
\hline Grade II & $34(60.71 \%)$ & $22(39.29 \%)$ & & Grade II & $18(32.1 \%)$ & $38(67.9 \%)$ & \\
\hline Grade III & $14(28 \%)$ & $36(72 \%)$ & & Grade III & $30(60 \%)$ & $20(40 \%)$ & \\
\hline \multicolumn{4}{|l|}{ Staging } & \multicolumn{4}{|l|}{ Staging } \\
\hline Stage I & $28(93.33 \%)$ & $2(6.67 \%)$ & \multirow{4}{*}{$<0.001$} & Stage I & $2(6.7 \%)$ & $28(93.3 \%)$ & \multirow{4}{*}{$<0.001$} \\
\hline Stage II & $16(88.89 \%)$ & $2(11.11 \%)$ & & Stage II & $2(11.1 \%)$ & $16(88.9 \%)$ & \\
\hline Stage III & $12(42.86 \%)$ & $16(57.14 \%)$ & & Stage III & $14(50 \%)$ & $14(50 \%)$ & \\
\hline Stage IV & $10(18.52 \%)$ & $44(81.48 \%)$ & & Stage IV & $36(66.7 \%)$ & $18(33.3 \%)$ & \\
\hline
\end{tabular}

$28(21.5 \%)$ patients. Seventy-six $(58.5 \%)$ reported no known comorbidities. Forty-five (34.6\%) women had a positive family history of cancer. In the present study, endometrioid adenocarcinoma 98 (75.4\%) was the most commonly reported histology variant of endometrial cancer, followed by Serous 14 (10.8\%), and clear cell $8(6.2 \%)$. Over one-half of the women were positive for both ER and PR, while $54(41.5 \%)$ were negative for both ER and PR. Only, 6 (4.6\%) patients were positive for ER only while $4(3.1 \%)$ patients were positive for PR only (Table-I).

The current study found a statistically significant association of the estrogen and progesterone receptor with low grade (Grade I and II) tumours and with stage I and stage II endometrial carcinoma with $p$ $<0.001$ (Table-II).

In the present study, about $34(34.7 \%)$ cases were negative for both estrogen and progesterone receptors in patients with an endometrioid type of cancer. Over $3 / 4^{\text {th }}$ of both serous and clear cell type histology of endometrial carcinoma were negative for both ER and PR expression $(p=0.005)$. The estrogen and progesterone receptor negativity was strongly associated with poorly differentiated or Grade III endometrial cancer with a statistically significant $p$-value of 0.003 . Most of the stage IV cancers were negative for both the ER and PR receptors with a $p<0.001$. Parity and menopausal
Table-III: Association of estrogen and progesterone receptor positivity with clinical and histological characteristics of endometrial carcinoma.

\begin{tabular}{|c|c|c|c|}
\hline \multicolumn{4}{|c|}{ ER \& PR Negative } \\
\hline Variable & Yes & No & $p$-value \\
\hline \multicolumn{4}{|c|}{ Histological Variant } \\
\hline Endometrioid & $34(34.7 \%)$ & $64(65.3 \%)$ & \multirow{3}{*}{0.005} \\
\hline Serous & $10(71.4 \%)$ & $4(28.6 \%)$ & \\
\hline Clear cell & $6(75 \%)$ & $2(25 \%)$ & \\
\hline \multicolumn{4}{|l|}{ Parity } \\
\hline Nulliparous & $6(37.5 \%)$ & $10(62.5 \%)$ & \multirow{2}{*}{0.726} \\
\hline Parous & $48(42.1 \%)$ & $66(57.9 \%)$ & \\
\hline \multicolumn{4}{|l|}{ Menopausal Status } \\
\hline Premenopausal & $14(53.8 \%)$ & $12(46.2 \%)$ & \multirow{2}{*}{0.215} \\
\hline Postmenopausal & $42(40.4 \%)$ & $62(59.6 \%)$ & \\
\hline \multicolumn{4}{|l|}{ Grade } \\
\hline Grade I & $6(25 \%)$ & $18(75 \%)$ & \multirow{2}{*}{0.003} \\
\hline Grade II & $18(32.1 \%)$ & $38(67.9 \%)$ & \\
\hline
\end{tabular}

When staging was distributed according to the histology variants, it was observed that all Stage I \& Stage II cancers belonged to the endometrioid histology. In Stage III cancers, 14 (50\%) were of endometrioid adenocarcinoma subtype while only $4(14.3 \%)$ were serious types. In Stage IV, $36(66.7 \%)$ belonged to the endometrioid type of endometrial cancer, with 8 and 9 cases of clear cell and serous type respectively (Figure).

\section{DISCUSSION}

Traditionally, endometrial carcinoma is divided into two main subtypes i.e. type 1, which is estrogen- 


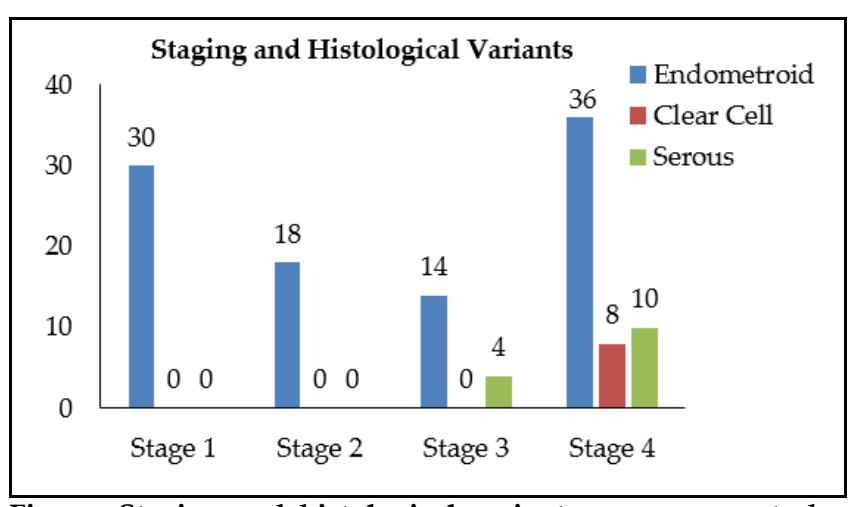

Figure: Staging and histological variants among our study participants.

dependent and Type 2 which is estrogen-independent. Type 1 has been associated with less aggressive histology and a better prognosis. On the other hand, type 2 has been shown to be more aggressive in nature with ER/PR negativity ${ }^{10}$. Endometrioid adenocarcinoma histology is usually estrogen and progesterone receptor expression positive while serous and clear cell carcinoma is ER/PR negative tumors ${ }^{11}$. The other classification is dependent upon the metabolic, endocrine, and clinical characteristics of the disease. Type I cancers are known to be estrogen-driven tumours, more commonly associated with obesity, hormone receptor positivity, and endometrial hyperplasia. These cancers have a better prognosis with a lower grade disease at the time of diagnosis. Type-II cancers are non-estrogenic, more common in lean patients with hormone receptor-negative status. These types of cancers carry a poorer prognosis ${ }^{12}$.

The present study reported significant findings with respect to endometrial carcinoma in a tertiary care centre in Karachi. We observed the frequency of ER, PR positivity in $33(50.80 \%)$ patients and ER, PR negativity in $27(41.5 \%)$ patients. It was found that more than half the patients were positive for both estrogen and progesterone receptors. We also observed a strong correlation of endometrioid histology with estrogen and progesterone receptor positivity $(p<0.05)$. In a recent systematic review and meta-analysis of over 98 studies, estrogen and progesterone receptor expression were linked with favourable prognosis and clinical outcome. The determination of hormone receptor status holds immense significance in prognostic evaluation among patients ${ }^{13}$. In the present study, more aggressive subtypes i.e. serous and clear cell histology were significantly correlated with the absence of both ER and PR expression. This finding is in accordance with another study where aggressive malignancies of endometrial carcinoma have been associated with HER2 over-expression and absence of ER and PR expression. Both serious and clear cell histology is associated with poor prognosis and lower survival rates ${ }^{14}$. Unfortunately, in our setting evaluation of hormone receptor expression is not routinely done. Management and treatment plans are largely based on histological variants, the grade, the stage of cancer and other associated clinical factors.

Endometrioid adenocarcinoma histology was the most frequently reported endometrial cancer in our setting. Other reported subtypes were clear cell and serous. Out of $80 \%$ of patients were postmenopausal at the time of the diagnosis. Our findings are in agreement with the studies conducted by Fanning, Ambros, and Hernandez et al15-17. In a Norwegian study, it was reported that about $79 \%$ of their patients with diagnosed endometrial cancer belonged to the endometrioid histological subtype ${ }^{18}$. The majority of them were moderately differentiated, carried a better prognosis and increased survival rate. In contrast to some studies ${ }^{19}$, our study reported that the majority of the patients had moderately to poorly differentiated disease at the time of diagnosis. High-grade endometrial cancers were historically associated with hormone replacement therapy or in breast cancer patients who were treated with Tamoxifen ${ }^{20}$.

Endometrial cancer is often diagnosed at an early stage while, in the present study, the majority of the patients were diagnosed at an advanced stage or presented with a high-grade carcinoma. The contradictory findings can be explained by the fact that in poor-income countries like Pakistan, the health care of women and children are greatly compromised. The women in Pakistan often do not inform their spouses or family members of any symptoms they experience out of shame. One of the most common manifestations of endometrial carcinoma is postmenopausal bleeding 21 . The risk of endometrial carcinoma in women with postmenopausal bleeding increases with age from $1 \%$ at the age of 50 years to approximately $25 \%$ at the age of 80 years ${ }^{22-23}$. However, due to a lack of health education and awareness, many women do not get a consultation from their primary physicians and present very late in the course of the disease when the symptoms become unmanageable.

As stated earlier, $80 \%$ of the patients in the present study were postmenopausal at the time of diagnosis. This finding may coincide with the studies from European countries where a rise in postmenopausal 
women with diagnosed endometrial cancer has been observed, more specifically in Northern and Western countries. One recent Chinese study has reported menopausal status to be of significant importance with the majority of the patients presenting after menopause ${ }^{23}$. However, a contrast in trend has been observed in Denmark, France, and Switzerland ${ }^{24}$. This high frequency of endometrial cancer in postmenopausal women can be explained by the changes in reproductive behaviour and prevalence of overweight and obesity among women, and also an increase in the use of hormone replacement therapy. The recent rise in the use of combined oral contraceptives (COCP) among our population may explain a decline in endometrial cancer in younger women.

The present study also evaluated the association of certain known risk factors with ER and PR expression. Nulliparity and Menopausal status did not have any significant association, while Grade and Stage of tumour were significantly associated with ER and PR expression $(p<0.005)$. This finding is in line with other studies where steroid expression is associated with low-grade disease and a better survival rate ${ }^{25}$.

\section{LIMITATION OF STUDY}

One of the limitations of this present study is the limited sample size. Another limitation could be the lack of certain variables including HER2 receptor expression, Body Mass Index (BMI) of patients, and a more detailed reproductive history of patients. Future researches can be focused on evaluating targeted therapy for endometrial cancer concerning the risk factors and prognostic factors.

\section{CONCLUSION}

The present study reported a high frequency of ER and PR positive expression. The most common histology observed was endometrioid adenocarcinoma histology. Our study also highlighted the strong association of ER and PR expression with grade, histology and stage of the tumour. ER and PR receptor positivity may have prognostic value and can be exploited to develop more targeted therapy.

Conflict of Interest: None.

\section{Authors' Contribution}

AS: Conception, data collection, GH: Supervision of data, critical review, PM: Data review, data acquisition, SB: Manuscript writing, MS: Statistical analysis, KA: Manuscript writing.

\section{REFERENCES}

1. Lortet-Tieulent J, Ferlay J, Bray F, Jemal A. International patterns and trends in endometrial cancer incidence, 1978-2013. J Natl Cancer Inst 2017; 110(4): 354-361.

2. Amant F, Moerman P, Neven P, Timmerman D, Van-Limbergen E, Vergote I. Endometrial cancer. Lancet 2005; 366(9484): 491-505.

3. Sorosky JI. Endometrial cancer. Obstet Gynecol 2012; 120 (2 Part 1): 383-397.
4. Elwood JM, Cole P, Rothman KJ, Kaplan SD. Epidemiology of endometrial cancer. J Natl Cancer Inst 1977; 59(4): 1055-1060.

5. Brinton LA, Felix AS, McMeekin DS, Creasman WT. Etiologic heterogeneity in endometrial cancer: evidence from a gynecologic Oncology Group trial. Gynecol Oncol 2013; 129(2): 277-284.

6. Linkov F, Edwards R, Balk J, Yurkovetsky Z, Stadterman B, Lokshin A, et al. Endometrial hyperplasia, endometrial cancer and prevention: gaps in existing research of modifiable risk factors. Eur J Cancer 2008; 44(12): 1632-1644.

7. Srijaipracharoen S, Tangjitgamol S, Tanvanich S, Manusirivithaya S, Khunnarong J, Thavaramara T, et al. Expression of ER, PR, and Her2/neu in endometrial cancer: a clinicopathological study. Asian Pac J Cancer Prev 2010; 11(1): 215-220.

8. Köbel M, Atenafu EG, Rambau PF, Ferguson SE, Nelson GS, Ho TC, et al. Progesterone receptor expression is associated with longer overall survival within high-grade histotypes of endometrial carcinoma: A Canadian high-risk endometrial cancer consortium (CHREC) study. Gynecol Oncol 2016; 141(3): 559-563.

9. Shen F, Gao Y, Ding J, Chen Q. Is the positivity of estrogen receptor or progesterone receptor different between type 1 and type 2 endometrial cancer?. Oncotarg 2017; 8(1): 506-509.

10. Abid M, Hashmi AA, Malik B, Haroon S, Faridi N. Clinical pattern and spectrum of endometrial pathologies in patients with abnormal uterine bleeding in Pakistan: need to adopt a more conservative approach to treatment. BMC Women Health 2014; 14(1): 1-7.

11. Murali R, Soslow RA, Weigelt B. Classification of endometrial carcinoma: more than two types. Lancet Oncol 2014; 15(7): e268-e278.

12. Bokhman JV. Two pathogenetic types of endometrial carcinoma. Gynecol Oncol 1983; 15(1): 10-17.

13. Zhang Y, Zhao D, Gong C, Zhang F, He J, Zhang W, et al. Prognostic role of hormone receptors in endometrial cancer: a systematic review and meta-analysis. World J Surg Oncol 2015; 13(1): 208-212.

14. Brack S, Attinger-Toller I, Schade B, Mourlane F, Klupsch K. A bispecific HER2-targeting FynomAb with superior antitumor activity and novel mode of action. Mol Cancer Ther 2014; 13(8): 2030-2039.

15. Fanning J, Evans MC, Peters AJ, Samuel M, Harmon ER, Bates JS. Endometrial adenocarcinoma histologic subtypes: clinical and pathologic profile. Gynecol Oncol 1989; 32(3): 288-291.

16. Ambros RA, Kurman RJ. Combined assessment of vascular and myometrial invasion as a model to predict prognosis in stage I endometrioid adenocarcinoma of the uterine corpus. Cancer 1992; 69(6): 1424-1431.

17. Hernandez E. Pathological findings and prognosis from uterine malignancy. Curr Opin Obstet Gynecol 1993; 5(4): 480-485.

18. Abeler VM, Kjørstad KE. Endometrial adenocarcinoma in Norway. A study of a total population. Cancer 1991; 67(12): 3093-3103.

19. Morice P, Leary A, Creutzberg C, Abu-Rustum N, Darai E. Endometrial cancer. Lancet 2016; 387(10023): 1094-1108.

20. Magriples U, Naftolin F, Schwartz PE, Carcangiu ML. High-grade endometrial carcinoma in tamoxifen-treated breast cancer patients. J Clin Oncol 1993; 11(3): 485-490.

21. Gredmark T, Kvint S, Havel G, Mattsson LA. Histopathological findings in women with postmenopausal bleeding. BJOG 1995; 102(2): 133-136.

22. Yousaf S, Shaheen M, Rana T. Frequency of endometrial carcinoma in patients with postmenopausal bleeding. Ann King Edw Med Univ 2010; 16(4): 290-295.

23. Gao Y, Zhao M, Dai X, Tong M, Wei J, Chen Q. The prevalence of endometrial cancer in pre-and postmenopausal Chinese women. Menop 2016; 23(8): 884-887.

24. Bray F, dos Santos Silva I, Moller H, Weiderpass E. Endometrial cancer incidence trends in Europe: underlying determinants and prospects for prevention. Cancer Epidemiol Biomark Prev 2005; 14(5): 1132-1142.

25. Jeon YT, Park IA, Kim YB, Kim JW, Park NH, Kang SB, et al. Steroid receptor expressions in endometrial cancer: clinical significance and epidemiological implication. Cancer Lett 2006; 239(2): 198-204. 